\title{
Written debriefing: Evaluating the impact of the addition of a written component when debriefing simulations
}

Shelly Jensen Reed

Brigham Young University - Provo, shelly-reed@byu.edu

Follow this and additional works at: https://scholarsarchive.byu.edu/facpub

Part of the Other Nursing Commons

\section{Original Publication Citation}

Reed, S. J. (2015). Written debriefing: Evaluating the impact of the addition of a written component when debriefing simulations. Nurse Education in Practice, 15(6) 543-548.

\section{BYU ScholarsArchive Citation}

Reed, Shelly Jensen, "Written debriefing: Evaluating the impact of the addition of a written component when debriefing simulations" (2015). Faculty Publications. 5323.

https://scholarsarchive.byu.edu/facpub/5323 


\title{
Written debriefing: Evaluating the impact of the addition of a written component when debriefing simulations
}

\author{
Shelly J. Reed* \\ Brigham Young University, 530 SWKT, Provo, UT 84602, USA
}

\section{A R T I C L E I N F O}

\section{Article history:}

Received 12 September 2014

Received in revised form

6 February 2015

Accepted 28 July 2015

Keywords:

Simulation

Debriefing

Written debriefing

Journaling

Blogging

Reflection

\begin{abstract}
A B S T R A C T
Debriefing, the reflective period following a simulation, is said to be where the bulk of simulation learning takes place. Many expert opinions regarding debriefing exist, but evidence-based best practices have yet to be identified. Written debriefing is one of these practices; experts state learning can be extended through the addition of a written component to the debriefing process, but no evidence exists to support this. This study compares three debriefing types: discussion alone, and discussion followed by journaling or blogging. Undergraduate nursing students participating in a simulation were randomized as a simulation group to one of these three debriefing types. Following completion of debriefing activities, students completed a Debriefing Experience Scale, a tool designed to evaluate the student experience during debriefing. Data obtained from completed scales were analyzed with ANOVA followed by Fisher LSD post hoc testing. The results showed the students preferred their experience with discussion debriefing over discussion debriefing with a written component added.
\end{abstract}

(C) 2015 Elsevier Ltd. All rights reserved.

\section{Introduction}

Simulation is an interactive and effective technology providing learning for nursing students through simulated clinical situations, where students can practice clinical skills, decision making, assessment, teamwork, communication and problem solving. In addition, simulation can be used by educators to evaluate student skills and proficiencies, as well as to provide simulated clinical situations that are not usually found in traditional clinical settings (Alderman, 2012; Cato, 2012; Harder, 2009; Jeffries et al., 2009; Reed, 2009). One of the most important parts of a simulation learning is debriefing, the reflective exercise that follows a simulation. It is vital to the overall simulation exercise, and is said to be where the bulk of the learning takes place (Shinnick et al., 2011).

The objective of debriefing is for the facilitator(s) and participants to engage and reflect upon the simulated clinical experience (Gum et al., 2011). The best way to provide this reflection has not been established, with nurse educators relying on journal articles, conference presentations, individual teaching experience, and student feedback to guide current debriefing practice (Waznonis, 2014). Considerations for debriefing should include the learning

\footnotetext{
* Tel.: +1 801712 8100; fax: +1 8014222348

E-mail address: shelly-reed@byu.edu.
}

objectives for the debriefing session, the learners, and the type of simulation being debriefed (Reed et al., 2013). The format of debriefing varies among institutions. The best structure or framework has not yet been identified, but there is an emphasis on the literature linked to debriefing facilitator demeanor. Facilitators should display interest in student learning, encouraging students to answer their own questions to facilitate critical thinking and clinical reasoning (Neill and Wotton, 2011). There are many expert opinions about how debriefing should be structured, but there is little evidence concerning specific debriefing practices that best contribute to learning, with unanswered questions on how to debrief, when to debrief, and whom to include in debriefing (Dreifuerst, 2009; Waznonis, 2014).

At present, debriefing practices generally involve a facilitatorled discussion of the simulation, with a review of the videorecorded simulation sometimes added to provide a focus (Reed et al., 2013). In addition to discussion and video review, writing has been suggested to extend the learning found in debriefing (Petranek, 2000); however, the use of writing in debriefing nursing simulations is unstudied.

\section{Purpose}

The purpose of the research was to explore the impact of adding written debriefing to the nursing student debriefing experience. 


\section{Background/literature review}

Simulation learning has increased rapidly in healthcare, with increasing support from health care and nursing organizations. Simulation uses cognitive, affective and psychomotor skills to create an active learning environment for students (Arafeh et al., 2010; Waznonis, 2014). A central component in the simulation learning process is debriefing, an interactive discussion between students and facilitator that provides feedback to students on the basis of their performance (Neill and Wotton, 2011). A planned debriefing experience should be a part of every simulation experience; in fact, learners themselves report debriefing to be the most important part of simulation (INACSL, 2011).

Debriefing is the reflective period following a simulation, designed to solidify learning in an experiential exercise. It is guided by the learning objectives of the simulation, and should be attended by those group members, including the facilitator, that participated in the simulation. The facilitator is vital to the debriefing discussion, helping students to process the simulation experience and gain knowledge from it. Feelings about and reactions to the simulation are discussed. Actions of group members during the simulation are analyzed, drawing on prior knowledge, with the purpose of linking lessons learned to future clinical situations. Feedback is not only given by the facilitator, but also by other group members, with the discussion including topics such as behavior and decision making. The debriefing should end with a summary to reinforce the learning objectives (Arafeh et al., 2010; Dreifuerst, 2009; Neill and Wotton, 2011; Reed, 2013).

Current debriefing practice usually includes a facilitated discussion of the simulation, with this discussion sometimes augmented by a review of parts or the entire videotape of the simulation performance. Debriefing generally follows right after the simulation, to allow diffusion of emotions, although methods such as videotape review can be utilised at a later time. Expert opinions on how to debrief are widely published across disciplines with the differing debriefing styles showing purported benefits. Actual simulation practices in nursing education are not widely known, with little research available to compare debriefing styles and to guide best practices (Cantrell, 2008; Neill and Wotton, 2011; Waznonis, 2014). The available studies examining debriefing show potential effectiveness of alternate debriefing methods, but there is need for more research comparing and exploring debriefing methods (Dufrene and Young, 2014).

As early as 1992, and again in 2000, Petranek suggested knowledge gained from a simulation can be extended by adding post reflection writing, stating "simulations ... provide three levels of learning: through participating, debriefing and writing" (Petranek et al., 1992, p 174). He proposes that oral debriefing assumes that everyone has learned the same lessons, while written debriefing allows individual learning and interpretation at a higher level (Petranek, 2000). Written debriefing is said to provide more opportunities to deliberate and reflect, with the exercise of writing providing articulation of thoughts not found through discussion alone (Van der Meij et al., 2013). Journaling provides other advantages as well, such as connecting experiences and the classroom, gaining the perspective of others through self-analysis of nursing transactions, developing critical thinking and problem solving skills, and reflecting on professional roles (Blake, 2005).

A study of simulation debriefing comparing discussion, journaling, and blogging with 100 undergraduate nursing students showed the students preferred discussion. Preference for the use of discussion to debrief was primarily because of the immediacy and interactivity that came with the discussion following the simulation, as compared to the time lag and separation from the debriefing group that accompanied completion of the writing activities (Reed, 2009). Potential positives for using written debriefing are posed in the new National League of Nursing simulation text. These include prompting personal reflection and reframing of experiences, with the time involved for journaling leading to deeper processing of experiences (Dreifuerst and Decker, 2012).

While Petranek was referring to a journal when discussing the use of writing for debriefing, learners today have other options for written reflection. Today's nurse learners are primarily of the millennial generation; those who are 16-29 years old. This is the "wired" generation, where "technology is their native tongue" (Wieck, 2011). Millenials, born from 1982 to 2002 are the traditional students attending nursing classes. They have grown up with computers, internet access around the clock, and with information at their fingertips. They have been raised to do things in teams, prefer group projects and may have difficulty thinking outside the group (Johnson and Romanello, 2005).

A newer form of journaling that is compatible with the millennial generation is a web-log or blog. A blog is a journal on the web, on a specifically labeled website. Blogs can be suitable for large or small group online conversations, in fact, only a few blogs ever obtain large readership. Blogs can be personalized, privatized, and are easily updated and created. While the major value of a blog is its content, the interactive capability of a blog helps to foster social interaction as well (Du and Wagner, 2006). This social interaction provides a platform for learning, as comments are read and responded to, providing a venue for group reflection on issues and learning experiences. In addition, blogging allows asynchronous discussion, affording learners the flexibility to have time to think about the discussion and record messages and replies that can be accessed repeatedly (Mohamad et al., 2013).

\section{Method}

\section{Design}

An experimental study design was used to compare nursing student experiences between three debriefing types: discussion only debriefing (discussion), discussion debriefing followed by blogging (blogging), and discussion debriefing followed by journaling (journaling).

\section{Sample}

The sample for the study was a convenience sample of 58 nursing students in an obstetric nursing course attending a baccalaureate nursing program at a university in the western United States. Students attending the course are primarily Caucasian and female; less than 10 percent of the students are of minority status or are male. The semester from which the sample was obtained had an average age of 21.4 years and was the fourth semester of a seven-semester curriculum. Students in this course had participated in 5-6 simulation/debriefing exercises up to that point in their schooling. The debriefing session followed participation in a standardized postpartum hemorrhage simulation as part of the curriculum for the course. Prior to this study, students had participated in only discussion debriefing after their simulations.

\section{Instrument of data collection}

The tool used for the study is the Debriefing Experience Scale, designed to evaluate the nursing student experience during debriefing. The scale consists of 20 items rated separately in the area of "experience" and "importance" to the student, making it two scales in one. Cronbach's alpha for the "experience" portion of 
the scale is .93 and for the "importance" portion is .91 . The 20 items are divided into four subscales, obtained through factor analysis during development of the scale. Only the "experience" portion of the scale was used for this study. Subscales and Cronbach's alpha for this portion are: Analyzing Thoughts and Feelings (.80); Learning and Making Connections (.89); Facilitator Skill in Conducting the Debriefing (.80); and Appropriate Facilitator Guidance (.84). The 20 items were rated from 1 to 5 in Likert-type rating, from 1 (strongly disagree) to 5 (strongly agree). The tool also has an area for written comments. Validity of the scale was established through review of the items by three nationally known simulation experts as well as through a two-step factor analysis process (Reed, 2009, 2012). Individual items on the scale are listed in Table 1.

\section{Data collection and statistical analysis}

University Institutional Review Board permission was obtained for the study. No compensation or additional course points were given for study participation. Points for the simulation and debriefing were given upon completion of the activities, as they are already part of the course curriculum, with students completing the simulation and debriefing receiving all of their points (no partial points were given). As the investigator was one of four faculty members teaching in the obstetric course, the study was explained by a non-faculty research assistant in the class period prior to the simulation without the investigator present. Study participation was defined as completion of the DES following debriefing, and students were informed that this was a voluntary activity as nonparticipation did not result in any point deduction.

Random assignment to a debriefing type was made for each group by drawing the debriefing assignment out of a hat, replacing the assignment before drawing for the next group. Groups, including both students and facilitators, were not informed of the assignment until after the simulation scenario had been completed.
Each group then completed discussion debriefing. Following debriefing, the study was briefly explained again by the research assistant, and all students were given an Informed Consent and a Debriefing Experience Scale (DES) if they were interested in participating. All 58 students in the simulation groups chose to take an informed consent and scale. Discussion only participants were told they could complete the DES in a location of their choosing, but should turn it in to the personnel at the Nursing Learning Center reference desk within one week.

Those groups who had been randomized to written debriefing by journaling or blogging were given a written page of instructions for completing their written debriefing activity. In addition, students interested in participating in the study were given a copy of the DES in a sealed envelope by a research assistant and were asked to open the envelope and complete the scale once journaling or blogging was completed. Brief instructions for completing the debriefing activity were on the outside of the envelope, with directions to turn in completed scales to the reference desk at the Nursing Learning Center (NLC) within one week of completing debriefing. NLC employees took the completed forms that had been returned and separated the Informed Consent document and DES in separate files in a locked box kept behind the desk in an area not accessible to students. One week after the last debriefing was completed the box was removed from the NLC by the investigator, with documents kept in either the locked box or a locked private office during data analysis.

Data obtained from completed scales was input into SPSS using double entry. Data was then cleaned and statistically analyzed using IBM SPSS version 19.0 by a one-way ANOVA and Fisher's LSD post-hoc testing.

\section{Debriefing}

Following a 35 minute simulation, students in all debriefing types had a twenty minute discussion debriefing. The facilitators

Table 1

ANOVA, discussion only debriefing $(\mathrm{N}=15)$; discussion with journaling $(\mathrm{N}=20)$; discussion with blogging $(\mathrm{N}=13)$.

\begin{tabular}{|c|c|c|c|c|c|c|c|c|}
\hline \multirow[t]{2}{*}{ Subscale/number of items } & \multicolumn{2}{|c|}{ Discussion only } & \multicolumn{2}{|c|}{$\begin{array}{l}\text { With } \\
\text { journaling }\end{array}$} & \multicolumn{2}{|c|}{$\begin{array}{l}\text { With } \\
\text { blogging }\end{array}$} & \multirow[t]{2}{*}{$p$} & \multirow[t]{2}{*}{$F$} \\
\hline & $M$ & $S D$ & $M$ & $S D$ & $M$ & $S D$ & & \\
\hline \multicolumn{9}{|l|}{ Analyzing Thoughts \& Feelings (4 items) } \\
\hline Debriefing helped me to analyze my thoughts & 4.5 & .52 & 4.5 & .52 & 4.2 & .83 & .401 & 9.33 \\
\hline The facilitator reinforced aspect of the health care team's behavior & 4.5 & .64 & 4.6 & .69 & 4.6 & .51 & .942 & 0.06 \\
\hline The debriefing environment was physically comfortable & $4.8(\mathrm{a}, \mathrm{b})$ & .41 & 4.3 & .65 & 4.1 & .95 & $.020^{*}$ & 4.29 \\
\hline Unsettled feelings from the simulation were resolved by debriefing & 4.3 & .46 & 4.3 & .65 & 3.8 & .94 & .186 & 1.75 \\
\hline \multicolumn{9}{|l|}{ Learning and Making Connections (8 items) } \\
\hline Debriefing helped me to make connections in my learning & $4.5(\mathrm{a})$ & .52 & $4.5(c)$ & .52 & 4.0 & .82 & .059 & 3.03 \\
\hline Debriefing was helpful in processing the simulation experience & $4.8(a)$ & .43 & 4.4 & .62 & 4.2 & .90 & .057 & 3.07 \\
\hline Debriefing provided me with a learning opportunity & $4.7(\mathrm{a})$ & .47 & 4.4 & .70 & 4.0 & .82 & $.031^{*}$ & 3.78 \\
\hline Debriefing helped me to find meaning in the simulation & 4.5 & .52 & 4.2 & .65 & 4.1 & .95 & .301 & 1.23 \\
\hline My questions from the simulation were answered by debriefing & 4.6 & .50 & 4.4 & .61 & 4.2 & .83 & .260 & 1.39 \\
\hline I became more aware of myself during the debriefing session & 4.2 & .70 & 4.1 & .83 & 3.7 & 1.03 & .256 & 1.41 \\
\hline Debriefing helped me to clarify problems & $4.6(a)$ & .50 & $4.4(c)$ & .61 & 3.8 & .80 & $.008^{*}$ & 5.45 \\
\hline \multicolumn{9}{|l|}{ Facilitator Skill in Conducting the Debriefing (5 items) } \\
\hline The facilitator allowed me enough time to verbalize my feelings before commenting & 4.4 & .75 & 4.4 & .86 & 4.3 & .85 & .895 & 0.11 \\
\hline The debriefing session facilitator talked the right amount during debriefing & 4.6 & .51 & 4.3 & .69 & 4.4 & .72 & .647 & 0.44 \\
\hline Debriefing provided a means for me to reflect on my actions during the simulation & 4.4 & .63 & $4.5(c)$ & .49 & 4.2 & .80 & .088 & 2.57 \\
\hline I had enough time to debrief thoroughly & 4.4 & .74 & 4.2 & .88 & 3.9 & .99 & .299 & 1.24 \\
\hline $\begin{array}{l}\text { The debriefing session facilitator was an expert in the content area } \\
\text { Appropriate Facilitator Guidance ( } 3 \text { items) }\end{array}$ & 4.9 & .36 & 4.7 & .59 & 4.4 & .96 & .195 & 1.70 \\
\hline The facilitator taught the right amount during the debriefing session & 4.5 & .83 & 4.3 & .67 & 4.3 & .86 & .819 & 0.20 \\
\hline The facilitator provided constructive evaluation of the simulation during debriefing & 4.3 & 1.03 & 4.3 & .82 & 4.3 & .94 & .987 & 0.10 \\
\hline The facilitator provided adequate guidance during the debriefing & $4.7(a)$ & .47 & 4.5 & .61 & 4.2 & .90 & .106 & 2.37 \\
\hline
\end{tabular}

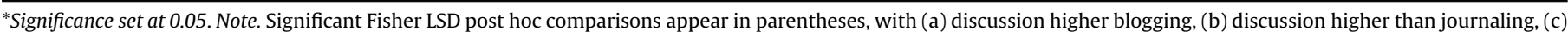
journaling higher than blogging. 
guided the discussion using five questions, formulated from an aviation model. The questions were:

1. What did you learn during the simulation session?

2. What did you think of your performance during the simulation?

3. What did you think of the group's performance during the simulation?

4. What are your questions concerning the simulation?

5. How can what you learned be applied to your future performance?

\section{(McDonnell et al., 1997)}

The discussion was led by the same facilitator who had facilitated the simulation session. Two of the three facilitators used for the simulation and debriefings (one facilitator per session) had no formal debriefing training; the third had attended a 3-day simulation training session sponsored by a simulation center, with the debriefing training provided not associated with any specific debriefing method. All of the facilitators had at least two years of experience running simulation and debriefing sessions.

Written debriefing was completed by either journaling or blogging. Journaling was accomplished by e-mail. At the end of discussion debriefing, the investigator obtained e-mail addresses of each group participant and the facilitator. A copy of the five debriefing prompts (the same five prompts for discussion debriefing) was e-mailed to the journaling participants. Participants were instructed to address the prompts in their journal entry, send the journal to their debriefing facilitator, and should then expect a response from the facilitator. A two-day limit was given to complete journaling activities for both the student and the facilitator.

Blogging was accomplished by using a private blog, set up through Blogger ${ }^{\circledR}\left(\right.$ Google $\left.^{\circledR}\right)$, with a patterned background and pictures from the simulation posted to add interest to the blog. At the end of the debriefing discussion, the investigator obtained e-mail addresses of each group participant and the facilitator. As permission is required to access a private blog, the investigator sent an invitation by e-mail to the students as soon as discussion debriefing was completed. Through privacy controls, access for the blog was limited to the participants, the facilitator, and the investigator; in addition, the blog was also restricted from search engines. Blogging participants were given the instructions to start blogging within two hours of the simulation, to allow better recall of the simulation experience. Expectations for completing the blogging activity include five blog entries, either discussing one or more of the five debriefing prompts as listed on the blog, or in response to another student's post or comment. The debriefing prompts for posting on the blog were the same five prompts used to guide discussion debriefing. Blog entries were to be completed within two days. After the two days, students were instructed to open the envelope and complete the DES and then return it to the reference desk at the Nursing Learning Center.

\section{Results}

Forty-eight of the 58 nursing students in the course chose to participate in the study by returning completed scales (83\% return rate). Fifteen returned the scales in the discussion only group, ( $83 \%$ return rate), 20 returning completed scales in the journaling group (83\% return rate), and 13 returning scales for the blogging group ( $81 \%$ return rate). Demographic information such as age and race was not collected on the scales.

Overall DES scale means for the "experience" portion of the scale were highest for discussion-only, followed by journaling, and then by blogging. However, statistical significance was found only in three individual DES items showing students preferred discussion only debriefing over discussion followed by writing. These items were "The debriefing environment was physically comfortable" $F(2$, $44)=4.29, p=.020$, "Debriefing provided me with a learning opportunity" $F(2,42)=3.78, p=.031$, and "Debriefing helped me to clarify problems" $F(2,42)=5.45, p=.008$ ) (Table 1 ).

The three different blogging groups had varied student participation. The first blogging group consisted of four students and their facilitator. Twenty posts were made addressing the five prompts meeting the minimum requirement set for blogging. Four comments were made in response to the student posts, all from the facilitator. Blogging group 2 consisted of 6 students and their facilitator. Only six posts were made regarding the five prompts, with 24 comments made in response to the posts. Three of the comments were from the session facilitator, indicating that overall; the students were short 3 comments/posts from meeting the minimum post/comment requirement. Blogging group 3 consisted of 6 students and their facilitator. This group made 14 posts and 25 comments, exceeding the required posts. The facilitator did not make any posts or comments, stating that she felt the students were discussing and answering their own questions through their comments.

Post hoc comparisons using the Fisher LSD test showed that students rated their experience with discussion only significantly higher than blogging on several items of the DES. This included the items "The debriefing environment was physically comfortable" $(p=.008)$; "Debriefing helped me to make connections in my learning" ( $p=.041)$; "Debriefing was helpful in processing the simulation experience" ( $p=.018)$; "Debriefing provided me with a learning opportunity" ( $p=.009)$; "Debriefing helped me to clarify problems" $(p=.002)$; "Debriefing helped me to make connections between theory and real-life situations" ( $p=.033)$; and "The facilitator provided adequate guidance during debriefing" $(p=.035)$.

Post hoc comparisons also showed that students rated their experience with discussion only significantly higher than journaling with the item "The debriefing environment was physically comfortable" $(p=.030)$. In addition, there were differences within the written methods as well, with students rating their experience with journaling higher than blogging in the items "Debriefing helped me to make connections in my learning" ( $p=.031)$; "Debriefing helped me to clarify problems" ( $p=.025)$; and "Debriefing provided me a means for me to reflect on my actions during the simulation" $(p=.032)$.

Reliability testing on the "experience" portion of the DES used for this study was performed. Cronbach's alpha for the overall "experience" portion of the scale was .89. Cronbach's alpha for the four "experience" subscales were: Analyzing Thoughts and Feelings (.65); Learning and Making Connections (.91); Facilitator Skill in Conducting the Debriefing (.87); and Appropriate Facilitator Guidance (.81).

Eight of the completed scales had comments on them, with five of these from blogging students and three were from the journaling students. Four of the five blogging comments were related to blogging as a debriefing method. The fifth blogging comment and those from journaling students were related to the overall simulation exercise. As there were so few comments, qualitative data analysis was not performed.

\section{Discussion}

It is important to identify evidence-based debriefing practices (Waznonis, 2014). Concerning the student experience with written debriefing, the results from this small study do not support 
Petranek's propositions in 1992 and 2000 that knowledge can be expanded with the addition of written debriefing. This was seen by students rating their experience with discussion alone over discussion followed by writing higher on four different items in the Learning and Making Connections subscale of the DES, as well as three other DES items.

Within the written debriefing methods, the results support the findings that students prefer self-debriefing (i.e. journaling) over collaborative debriefing (Van der Meij et al., 2013). While the students rated both journaling and blogging statistically lower than discussion alone, students did not react as negatively to journaling as they did blogging. The students in this course were born about the time Petranek first gave his suggestion to journal. They are of the Facebook generation, accustomed to information sharing. Students of this generation have grown up with technology and expect information presented in an entertaining way (Johnson and Romanello, 2005), such as written debriefing in the form of a blog (blogging). Data obtained from the DES showed that blogging did not appeal to these students.

In addition to results found from scale completion, student comments written on completed scales concerning blogging were primarily negative comments such as "Blogging was not helpful and really annoying" and "Having to write 5 entries was a hassle \& I thought it was awkward other students could read my feedback-especially what I thought about myself". For the effective use of blogging, some factors should be present, including establishing the utility of a blog, and need for an audience and comments (Kerwalla et al., 2009). Prior to this study, the student participants had only used discussion debriefing following simulation. This could have contributed to the "hassle" attitude, as students were accustomed to discussion only, and did not see a need for the blog, audience, or comments. Also, an advantage for journaling is that it allows private communication, allowing students the opportunity to express what they are thinking without worrying about peer review (Petranek, 2000). The inclusion of all session participants in each group blog did not provide private communication between facilitator and student, providing yet another explanation for student negativity toward blogging.

Different prompts or debriefing structures for oral and written debriefing could change the study results as well. Petranek suggests starting debriefing with an oral discussion using the prompts of the four E's of debriefing; events, emotions, empathy, and explanations, and then using these same "E's" to structure the written debriefing, with the best grades given for the most insightful analysis (Petranek et al., 1992). Structuring debriefing with these prompts and providing a grade for insightful comments would provide a different focus than the debriefing prompts and grading structure used for this study.

\section{Limitations}

Limitations for the study included participants from a single university, as well as small participant numbers, particularly with those students who participated in blogging. In addition, the short duration of exposure to both journaling and blogging (two days) may have affected the participant experience with written debriefing, as students tend to become more reflective as time passes (Xie et al., 2008). The use of three different debriefing facilitators was also a limitation, as the student debriefing experience would differ because of this factor. In addition, while perceived learning from a student perspective could be measured with the DES, actual learning provided by the three different debriefing methods was not measured.

\section{Conclusion}

In this study, students did not identify any benefit from the addition of a written debriefing component following discussion debriefing after a simulation. Regarding written debriefing accomplished through blogging, these students of a technologically savvy generation seemed more annoyed, than anything. The study would need to be repeated to confirm the results. Considerations for future studies would be the use of other writing prompts, or lengthening the time period for written debriefing, particularly blogging. Other written formats and/or social media platforms such as Facebook or university management systems could be used for the blogging portion. Another debriefing structure could be used to organize the debriefing, rather than the five prompts used. In addition, measuring learning achieved with something such as a standardized exam would also help to understand the impact of written debriefing on student learning. Additional studies would help to support or refute claims about the value of written debriefing.

\section{References}

Alderman, J.T., 2012. Using simulation to teach nursing students and licensed clinicians obstetric emergencies. Matern. Child. Nurs. 37 (6), 394-400.

Arafeh, J.M.R., Hansen, S., Nichols, A., 2010. Debriefing in simulated-based learning: facilitating a reflective discussion. J. Perinat. Neonat. Nurs. 24 (4), 302-309. http://dx.doi.org/10.1097/JPN.0b013e3181f6b5ec.

Blake, T.K., 2005. Journaling; an active learning technique. Int. J. Nurs. Educ. Scholarsh. 2 (1), 1-13.

Cantrell, M.A., 2008. The importance of debriefing in clinical simulations. Clin. Simul. Nurs. 4, e19-e23. http://dx.doi.org/10.1016/j.ecns.2008.06.006.

Cato, M.L., 2012. Using simulation in nursing education. In: Jeffries, P. (Ed.), Simulation in Nursing Education, second ed. National League for Nursing, New York, NY, pp. $1-10$.

Dreifuerst, K.T., Decker, S.I., 2012. Debriefing: an essential component for learning in simulation pedagogy. In: Jeffries, P. (Ed.), Simulation in Nursing Education, second ed. National League for Nursing, New York, NY, pp. 105-129.

Dreifuerst, K.T., 2009. The essentials of debriefing in simulation learning: a concept analysis. Nurs. Educ. Perspect. 30 (2), 109-114. http://dx.doi.org/10.1043/15365026-030.002.0109.

Du, H.S., Wagner, C., 2006. Weblog success: exploring the role of technology. Int. J, Hum. Comput. Stud. 64, 789-798.

Dufrene, C., Young, A., 2014. Successful debriefing-best methods to achieve positive learning outcomes: a literature review. Nurse Educ. Today 34, 372-376. http://dx.doi.org/10.1016/j.nedt.2013.06.026.

Gum, L., Greenhill, J., Dix, K., 2011. Sim TRACT: a reflective conceptual framework for simulation debriefing. J. Transform. Educ. 9 (1), 21-41.

Harder, B.N., 2009. Evolution of simulation use in health care education. Clin. Simul. Nurs. 5 (6), e169-e172. http://dx.doi.org/10.1016/j.ecns.2009.04.092.

Jeffries, P.R., Bambini, D., Hensel, D., Moorman, M., Washburn, J., 2009. Constructing maternal-child learning experiences using clinical simulations. J. Obstet. Gynecol. Neonat. Nurs. 38 (5), 613-623. http://dx.doi.org/10.1111/j.1552-6909. 2009.01060.

Johnson, S.A., Romanello, M.L., 2005. Generational diversity teaching and learning approaches. Nurse Educ. 30 (5), 212-216.

Kerwalla, L., Minocha, S., Kirkup, G., Conole, G., 2009. An empirically grounded framework to guide blogging in higher education. J. Comput. Assist. Learn. 25, $31-42$.

Mohamad, S.K., Tasir, Z., Harun, J., Shukor, N., 2013. Pattern of reflection in learning authoring system through blogging. Comput. Educ. 69, 356-368.

McDonnell, L.K., Jobe, K.K., Dismukes, R.K., 1997. Facilitating LOS debriefings: a training manual. NASA Tech. Memo. 112192, 1-43.

Neill, M.A., Wotton, K., 2011. High-fidelity simulation debriefing in nursing education: a literature review. Clin. Simul. Nurs. 7 (5), e161-e168.

Petranek, C.F., Corey, S., Black, R., 1992. Three levels of learning in simulations: participating, debriefing, and journal writing. Simul. Gam. 23 (2), 174-185.

Petranek, C.F., 2000. Written debriefing: the next vital step in learning with simulations. Simul. Gam. 31 (1), 108-118.

Reed, S.J., 2009. Comparison of Debriefing Methods Following Simulation: Development of Pilot Instrument (Doctoral thesis). Case Western Reserve University.

Reed, S.J., 2012 July. Debriefing experience scale: development of a tool to evaluate the student learning experience in debriefing. Clin. Simul. Nurs. 8 (6), e211-e217.

Reed, S.J., Andrews, C.M., Ravert, P., 2013. Debriefing simulations: comparison of debriefing with video and debriefing alone. Clin. Simul. Nurs. 9 (12), e585-e591. http://dx.doi.org/.1016/j.ecns.2013.05.007. 
Reed, S.J., 2013. Key concepts in simulation: debriefing and reflective practice. In: Ulrich, B., Mancini, M.E. (Eds.), Mastering Simulation: a Handbook for Success. Sigma Theta Tau, Indianapolis, pp. 125-141.

Shinnick, M.A., Woo, M., Horwich, T.B., Steadman, R., 2011. Debriefing: the most important component in simulation? Clin. Simul. Nurs. 7 (3), e105-e111.

The INASCL Board of Directors, 2011. Standard VI: the debriefing process. Clin. Simul. Nurs. 7 (4S), s16-s17.

Van der Meij, H., Leemkuil, H., Li, J., 2013. Does individual or collaborative selfdebriefing better enhance learning from games? Comput. Hum. Behav. 29, 2471-2479. http://dx.doi.org/10.1016/j.chb.2013.06.001.
Waznonis, A.R., 2014. Methods and evaluations for simulation debriefing in nursing education. J. Nurs. Educ. 53 (8), 459-465.

Wieck, K.L., 2011, August. Intergenerational chaos in modern academia: a kinder and gentler approach. In: Symposium Conducted at a Meeting of Brigham Young University College of Nursing, Provo, Utah.

Xie, Y., Ke, F., Sharma, P., 2008. The effect of peer feedback for blogging on college student's reflective learning processes. Internet High. Educ. 11, $18-25$. 